\title{
Kawasaki disease: guidelines of the Italian Society of Pediatrics, part I - definition, epidemiology, etiopathogenesis, clinical expression and management of the acute phase
}

Alessandra Marchesi ${ }^{1 *}$, Isabella Tarissi de Jacobis ${ }^{1}$, Donato Rigante ${ }^{2}$, Alessandro Rimini $^{3}$, Walter Malorni ${ }^{4}$, Giovanni Corsello ${ }^{5}$, Grazia Bossi ${ }^{6}$, Sabrina Buonuomo ${ }^{1}$, Fabio Cardinale ${ }^{7}$, Elisabetta Cortis ${ }^{8}$, Fabrizio De Benedetti ${ }^{1}$, Andrea De Zorzi ${ }^{1}$, Marzia Duse ${ }^{9}$, Domenico Del Principe ${ }^{10}$, Rosa Maria Dellepiane ${ }^{11}$, Livio D'Isanto ${ }^{12}$, Maya El Hachem ${ }^{1}$, Susanna Esposito ${ }^{13}$, Fernanda Falcini ${ }^{14}$, Ugo Giordano ${ }^{1}$, Maria Cristina Maggio ${ }^{5}$, Savina Mannarino ${ }^{6}$, Gianluigi Marseglia ${ }^{6}$, Silvana Martino ${ }^{15}$, Giulia Marucci ${ }^{1}$, Rossella Massaro ${ }^{16}$, Christian Pescosolido ${ }^{16}$, Donatella Pietraforte ${ }^{4}$, Maria Cristina Pietrogrande ${ }^{11}$, Patrizia Salice ${ }^{11}$, Aurelio Secinaro ${ }^{1}$, Elisabetta Straface ${ }^{4}$ and Alberto Villani ${ }^{1}$

\begin{abstract}
The primary purpose of these practical guidelines related to Kawasaki disease (KD) is to contribute to prompt diagnosis and appropriate treatment on the basis of different specialists' contributions in the field. A set of 40 recommendations is provided, divided in two parts: the first describes the definition of KD, its epidemiology, etiopathogenetic hints, presentation, clinical course and general management, including treatment of the acute phase, through specific 23 recommendations.

Their application is aimed at improving the rate of treatment with intravenous immunoglobulin and the overall potential development of coronary artery abnormalities in KD. Guidelines, however, should not be considered a norm that limits treatment options of pediatricians and practitioners, as treatment modalities other than those recommended may be required as a result of peculiar medical circumstances, patient's condition, and disease severity or complications.
\end{abstract}

Keywords: Kawasaki disease, Coronary artery abnormalities, Intravenous immunoglobulin, Aspirin, Children

\section{Background}

In 2008 the first Italian Kawasaki disease (KD) Guidelines were published. During the subsequent years new data have been collected and updated treatment reports have been published.

\section{Scope}

Scope of these revised guidelines is to update evidence on the following topics:

\footnotetext{
* Correspondence: alessandra.marchesi@opbg.net

${ }^{1}$ Bambino Gesù Children's Hospital, Rome, Italy, Piazza S. Onofrio n. 4, 00165 Rome, Italy

Full list of author information is available at the end of the article
}

- potential etiopathogenesis of KD;

- definition of clinical signs and symptoms, laboratory, and instrumental tests useful for KD diagnosis;

- efficacy of therapy for KD in the acute phase of the illness.

\section{Users}

These guidelines are directed to pediatricians who work in hospital, family pediatricians, and general practitioners who work with children affected by KD and for families of KD patients.

(c) The Author(s). 2018 Open Access This article is distributed under the terms of the Creative Commons Attribution 4.0 International License (http://creativecommons.org/licenses/by/4.0/), which permits unrestricted use, distribution, and reproduction in any medium, provided you give appropriate credit to the original author(s) and the source, provide a link to the Creative Commons license, and indicate if changes were made. The Creative Commons Public Domain Dedication waiver (http://creativecommons.org/publicdomain/zero/1.0/) applies to the data made available in this article, unless otherwise stated. 


\section{Note for users}

The clinical management of each patient with KD requires the application of these recommendations based on the peculiar patient's condition. We are pleased to publish updated diagnostic and therapeutic indications for both medical and paramedical staff as well as the most accurate information for families.

\section{Sponsorships}

No person who participated in the drafting of these guidelines has been sponsored.

\section{Dissemination}

The text has been initially discussed during the Consensus Conference "Kawasaki Disease: Italian Guidelines" in Rome during September 2015. The same text has been rediscussed in the 71st National Congress of the Italian Society of Pediatrics in Rome during June 2015, and finally approved in the 73th National Congress of the Italian Society of Pediatrics in Naples during June 2017.

\section{Updates}

Future updates are planned within the next 5 years, or sooner, if the medical literature will reveal evidence showing that these guidelines have become obsolete.

\section{Methods}

Different experts in general pediatric medicine, cardiology, infectious diseases, rheumatology, immuno-allergology, dermatology, radiology, or biologists experts in cell oxidative stress have participated in writing these guidelines. They have been supported by representatives of family associations. The team has been requested to systematically analyze the most recent literature about KD to define the following evidences dealing with etiopathogenesis, definition of clinical signs and symptoms, laboratory, and instrumental tests for diagnosis, efficacy of therapy with intravenous immunoglobulin and aspirin, efficacy of other therapies in the acute phase of KD.

The basic document was the Italian KD Guidelines, published in 2008 (Marchesi A, et al. Malattia di Kawasaki: Linee Guida italiane. Prospettive in Pediatria. 2008;38:266-83). Additionally, further references from the last 8 years were searched, using PubMed and Cochrane databases.

The following key-words were used: "child", "Kawasaki disease" or "Kawasaki syndrome", "coronary arteries aneurysm" and "ectasia", "echocardiography", "multislide computed tomography", "angiography", "intravenous immunoglobulin", "aspirin", "corticosteroids", limiting the search to documents on humans, written in English or Italian. Heterogeneity of the available researches and their low number did not allow to perform a meta-analysis of each item. The recommendations of these guidelines are based on the best evidences available. Stronger recommendations are based on high scientific quality data or, alternatively, on the consensus of experts. Clinical guidelines typically provide evidence levels based on the study design (Table 1) and reported effectiveness (Table 2).

\section{Introduction}

Nine years have passed since the first announcement of the Italian Guidelines for diagnosis and management of Kawasaki disease (KD) in a national journal, but recently many novel data and publications have become available in relationship with this acute systemic vasculitis of childhood [1]. According to the 2012 "Revised International Chapel Hill Consensus Conference Nomenclature of Vasculitides" [2], KD involves small and medium-sized vessels in each organ and tissue. The first KD cases were observed in Japan in 1962, and described by dr. Tomisaku Kawasaki in the article "Acute febrile mucocutaneous syndrome with lymphoid involvement with specific desquamation of the finger and the toes in children" in the 1967 journal Arerugi [3]. In general terms, we can consider KD as a self-limited heterogeneous disease with unknown etiology, which mostly affects infants and children under 5 years of age.

The most significant complications in KD are coronary artery aneurysms (CAA), but their overall incidence has been consistently reduced by treatment with intravenous immunoglobulin (IVIG) within 10 days of fever onset [4, 5]. Diagnosis of KD is merely clinic, based on the diagnostic clinical criteria, but may be supported by the results of various blood and instrumental exams. Actually, no clinical findings or tests can be considered specific for $\mathrm{KD}$, and this circumstance makes diagnosis especially challenging. Diagnostic difficulties depend on several causes, such as the different times at which clinical findings might appear, difficult discrimination with other infectious and non-infectious illnesses, protean clinical expression of the disease, occurrence of non-typical clinical findings, incomplete forms of the disease, absence of specific laboratory data, and even association with low acute phase reactants. Concurrently, a prompt recognition of KD is essential as its prognosis depends on the rapidity of treatment decision.

Goal of these guidelines is to recommend the best practice in both diagnosis and management of children

Table 1 Level (class) based on study design, defined as follows class I meta-analyses or systematic reviews from randomized controlled trials

class II single randomized controlled trials

class III nonrandomized controlled trials

class IV retrospective case-control studies

class $V$ number of cases without control group

class VI opinions of committees of experts and authorities 
Table 2 Classification (grade) based on effectiveness, defined as follows

grade A highly recommended

grade $\mathrm{B}$ recommended

grade $C$ recommended, but evidence is uncertain

grade $\mathrm{D}$ non recommended

grade E contraindicated

with $\mathrm{KD}$, based on the most actual scientific evidence, and improve the overall prognosis of this disease. These guidelines have been created for pediatricians working in hospital, family pediatricians, and general practitioners or nurses managing children affected by $\mathrm{KD}$ and for families of KD patients.

\section{Definition of Kawasaki disease Typical KD}

Typical or classic KD is characterized by the presence of $\geq 5$ days of fever and $\geq 4$ of the following main clinical features: bilateral non-exudative conjunctivitis, erythema of lips and oral mucosa, changes in the extremities, skin rash, and cervical lymphadenopathy. Cases with defervescence within the fifth day since disease onset should be included. Diagnosis of KD is based on the presence of the above clinical criteria: there are neither typical diagnostic features, nor specific diagnostic tests. These clinical criteria appear within 1-2 weeks, therefore the suspicion of KD may be initially problematic. The most fearful KD complications are CAA, which develop in 15 -to- $25 \%$ of untreated patients, but only in $5 \%$ of those treated with IVIG within 10 days following disease onset [6]. The medical literature has recently reported an increasing number of patients with incomplete and atypical KD.

\section{Incomplete $K D$}

Incomplete $\mathrm{KD}$ occurs in patients presenting a typical fever without a sufficient number of main clinical criteria, with or without CAA. This kind of KD is frequent in children younger than 12-24 months and should be suspected in every child younger than 6 months affected by fever for more than 7 days and a documented systemic inflammation, without any other possible cause [6].

\section{Atypical KD}

Atypical KD occurs in patients presenting a typical fever and signs or symptoms different from the main KD clinical features (i.e. meningeal inflammation, seizures, facial paralysis, acute abdomen, acute pancreatitis, cholestatic jaundice, arthritis, renal injury, pneumonia, etc.), with or without CAA [6].

Recommendation 1 Typical or classic KD is diagnosed if fever $\geq 5$ days associated with $\geq 4$ diagnostic criteria, with or without CAA, or if fever lasts at least for 4 days with $\geq 4$ diagnostic criteria and eventual demonstration of CAA on echocardiography.

$$
\text { (III - A) }
$$

Recommendation 2 Incomplete KD can be diagnosed when patients with fever for $\geq 5$ days lack a sufficient number of clinical criteria $(\leq 3)$ to fulfill the previous recommendation, with or without CAA.

$$
\text { (III - A) }
$$

Recommendation 3 Atypical KD is diagnosed if fever, not otherwise explained, lasting for $\geq 5$ days is associated with classic diagnostic criteria and non-classic manifestations, with or without CAA.

$$
\text { (III - A) }
$$

\section{Epidemiology of Kawasaki disease}

Epidemiologic data for KD are mainly available for Asia, Europe and North America, but there are also estimates for Australia, South America, Middle East, along with few data also from Africa [7-11]. The latest Italian data were produced in 1984 [12]. Studies on the spread of the disease have shown considerable differences between different geographical areas (Table 3), with incidence from 3.4 up to 218.6 cases per 100.000 children less than 5 years [7-13]. The overall incidence in Asia is, on average, at least 3-4 times higher in certain countries (Japan, Korea, China, Taiwan) rather than other (India, Thailand); these differences are even more significant in comparison with Europe and USA. It is likely that these differences are due to ethnic factors combined with environmental factors, but the different ability to recognize and report the disease should also be taken into account $[11,14,15]$. In fact, KD incidence in the Japanese population living in Hawaii is similar to those living in Japan [11]. The incidence of KD is different according to gender, as males are more prone to develop the disease, with a M:F ratio of 1,4-1,9:1 emerging from many studies [7-14].

Recent epidemiologic data showed an increased incidence of KD during the last decades, both into Western and Asiatic countries [7-9, 11, 13, 16, 17]: this is probably due to an improved ability for practitioners to recognize and diagnose $\mathrm{KD}$, especially in its incomplete form [11, 18]. For instance, in Australia the incidence has increased from 2.82 cases for 100.000 children of age $<5$ years during the decade 1980-1989 up to 9.34 cases during the decade 2000-2009 [9]. Due to this improvement, KD has become the leading cause of acquired heart disease in children living in developed countries [1, 11, 14].

With regards to age, KD is mostly observed in children less than 5 years in over $80 \%$ of cases $[8,15]$, with a peak incidence in the first 24 months of life $[11,14]$. However, there are also a few reports of $\mathrm{KD}$ in neonates, teenagers, and even in adults $[8,14]$. Such cases show a 
Table 3 Incidence rates of Kawasaki disease in Asia, Europe, and North-America

\begin{tabular}{|c|c|c|c|c|}
\hline Region & Period & Incidence ${ }^{a}$ & Source of data & Reference \\
\hline \multicolumn{5}{|l|}{ Asia } \\
\hline Japan & 2011-2012 & $243.1-264.8$ & National survey & Makino et al. 2015 [13] \\
\hline Japan & $2007-2008$ & 215.3-218.6 & National survey & Nakamura et al. 2010 [39] \\
\hline Korea & 2009-2011 & $115.4-134.4$ & National survey & Kim et al. 2014 [8] \\
\hline Corea & $2006-2008$ & 113.1 & National survey & Park et al. 2011 [28] \\
\hline Taiwan & $2003-2006$ & 69.0 & National Health System database & Huang et al. 2009 [40] \\
\hline \multicolumn{5}{|l|}{ China } \\
\hline -Bejing & 2004 & 55.1 & Beijing's Hospitals survey & Du et al. 2007 [41] \\
\hline -Shanghai & 2007 & 53.3 & Pediatric ward survey & Ma et al. 2010 [42] \\
\hline -Hong Kong & 1997-2000 & 39.0 & Retrospective and perspective analysis & Ng et al. 2005 [43] \\
\hline - Sichuan & 2001 & 9.81 & Hospital survey & Li et al. 2008 [44] \\
\hline India & 2007 & 4.5 & Retrospective analysis in Chandigarh, Northern India & Singh et al. 2011 [45] \\
\hline Thailand & 2002 & 3.4 & KD National Register & Durongpisitkul et al. 2006 [46] \\
\hline \multicolumn{5}{|l|}{ North America } \\
\hline Hawaii & 1996-2006 & 50.4 & Hawaii State Inpatient Database & Holman et al. 2010 [47] \\
\hline Canada & 2004-2006 & 26.2 & Clinical records' Review in Ontario & Lin et al. 2010 [48] \\
\hline \multicolumn{5}{|l|}{ South America } \\
\hline Chile & $2001-2007$ & 6.8 & National survey & Borzutzky et al. 2012 [49] \\
\hline \multicolumn{5}{|l|}{ Australia } \\
\hline \multirow[t]{3}{*}{ Western Australia } & 1980-1989 & 2.82 & ICD-9 review in Referral Hospital & Saundankar et al. 2014 [9] \\
\hline & 1990-1999 & 7.96 & & \\
\hline & 2000-2009 & 9.34 & & \\
\hline \multicolumn{5}{|l|}{ Middle- East } \\
\hline Israel & 1996-2009 & 6.4 & National Health System database & Bar-Meir, 2011 [10] \\
\hline \multicolumn{5}{|l|}{ Europe } \\
\hline United Kingdom & 1998-2003 & 8.4 & Hospitals' data & Harnden et al. 2009 [50] \\
\hline Ireland & $1996-2000$ & 15.2 & Ireland's Hospital In-Patient Enquiry database & Lynch et al. 2003 [51] \\
\hline Finland & 1992 & 7.2 & Recovery register & Salo et al. 1993 [52] \\
\hline Denmark & 1999-2004 & 4.9 & Danish National Hospital Register & Fischer et al. 2007 [53] \\
\hline Sweden & 1990-1992 & 6.2 & Clinical records & Schiller et al. 1995 [54] \\
\hline France & $2005-2006$ & 9.0 & Perspective survey in pediatric ward of Northen France & Heuclin et al. 2009 [55] \\
\hline Italy & 1981-1982 & 14.7 & Clinical records' Review and families'interview in Northen Italy & Tamburlini et al. 1984 [12] \\
\hline
\end{tabular}

${ }^{a}$ Incidence rates are reported per 100,000 children $<5$ years of age, with exclusion of India, for which they are reported per 100,000 children $<15$ years of age

tendency to develop CAA $[15,19]$, probably as a consequence of a late diagnosis.

Several studies demonstrate a seasonality pattern for $\mathrm{KD}$, with a peak incidence in late winter and during the spring-summer period, though this link into different geographical areas is weak $[7,8,11,20]$. The study of 25 different countries related to a large number of KD patients has shown a significant increase of cases during wintertime in extra-tropical regions of the Boreal hemisphere, with no significant correlation in the Austral hemisphere [21]. A recent theory suggests a link between tropospheric air currents and the epidemic diffusion of $\mathrm{KD}$, due to the transportation of mycotoxins from China and other areas of the Asian continent [22].

The average incidence for atypical and incomplete KD is between 15 and $36 \%$, with a higher distribution at the ends of the age distribution curve (i.e. for children $<1$ year and $>5$ years) $[23,24]$.

$\mathrm{KD}$ recurrence risk and incidence of familiar forms are well-documented in the Japanese medical literature and also in North-American studies [25-31]. In Japan the risk of illness for a sibling of a patient with KD is increased by 10 times in comparison with the general population [25], and the probability for children with 
KD to have a sibling with KD is between 0.17 and $1.6 \%$ [26-28]. This percentage is increased up to $13 \%$ for twins [29]; $50 \%$ of familiar cases occur, on average, up to 10 days later than the index case. Furthermore, $0.7 \%$ of Japanese cases with KD has at least one parent with a past history of $\mathrm{KD}[27,32]$. In Japan and Korea the overall recurrence risk is $3 \%[8,27,30]$, and the main risk factors are age $<3$ years and existence of cardiac sequelae [30].

In regards with $\mathrm{KD}$ complications, the incidence of CAA is approximately $15-25 \%$ in untreated patients and less than $5 \%$ in patients treated with IVIG within 10 days after the onset of fever [11, 19,33]. The risk of developing CAA is greater in children aged $<12$ months and $>$ 5 years, in males, and in the recurring forms of KD, as well as in the cases treated too late with IVIG [19, 20, 34]. In particular, infants younger than 6 months can develop CAA up to $65 \%$ of cases, even if correctly treated with IVIG [35]. The incidence of IVIG-resistant $\mathrm{KD}$ is $15-18 \%$ in relationship with the total number of cases and seems to have its main predictor in the presence of very high values of $C$-reactive protein (CRP) during KD acute phase [34, 36, 37].

Death related to KD is mostly due to cardiac sequelae, both in the short-term, with a peak of mortality between 15 and 45 days after the onset of fever, and in the long-term, even in adulthood: the mortality rate in patients with KD in Japan was more than 1\% up to 1974, and has decreased to 0.1 to $0.2 \%$ from 1974 to 1993 , with a further reduction between 1993 and 2002 to $0.02-0.09 \%$ and down to $0.01 \%$ in the most recent cases $[6,13,38,39]$. A Japanese survey in patients who developed KD between 1982 and 1992, followed up until 2009, has documented that those patients without CAA have a standardized mortality rate equivalent to the general population. On the other hand, those patients with cardiovascular involvement have a significantly higher standardized mortality rate [38].

\section{Etiopathogenesis of Kawasaki disease}

The definite etiology of $\mathrm{KD}$ is unknown: the identification of etiopathogenic mechanisms behind KD would be essential to develop preventive strategies and focused therapeutic strategies. Analyzing autoptic samples, plasma cells producing IgA have been identified in the wall of arteries of subjects with KD. Moreover, using synthetic IgA, intra-cytoplasmic inclusion bodies with virus-like particles have been found in intact tissue sections from children with KD, specifically in the ciliated epithelium of medium-sized bronchi $[56,57]$.

\section{From the pathophysiological point of view}

Arteritis develops around the eighth-ninth day after KD onset, and CAA start with edema formation in the intima and media of arteries and partial rupture of the internal and external elastic lamina. The arterial wall does not support the internal pressure, especially diastolic, and undergoes distension and deformation, leading to the formation of aneurysms. When aneurysms begin to calcify a further pathological distension may develop within $2-3$ years $[58,59]$.

\section{From the pathological point of view}

There are three phases in KD:

- Acute phase. It has a mean duration of 2 weeks and is characterized by a necrotizing vasculitis with a predominance of neutrophils and macrophages [60, 61].

- Subacute/chronic phase. It starts after 15 days and is characterized by the presence of lymphocytes, plasma cells and eosinophils, which migrate to the lumen and alter the adventitia.

- Convalescence phase. It is characterized by the proliferation of myofibroblasts that form a concentric mass, which progressively obliterates the lumen.

Acute phase and innate immunity The acute phase corresponds to the activation of innate immunity: changes begin from endothelium and progress to the adventitia; necrosis can gradually destroy the adventitia, resulting in ectasia or aneurysm formation, while platelets display a pro-coagulant phenotype in the second week. Further studies have shown that the interaction with activated platelets is necessary for the decision by neutrophils to migrate into the vessel wall or run into cell death with the formation of "extracellular traps" [62-68].

Subacute/chronic phase and acquired immunity The main actors of this phase are macrophages and lymphocytes. The infiltration of these cells starts from the internal elastic membrane or from the media. The resolution of inflammation may be followed by a later stage dominated by macrophages with a different phenotype (myeloid-derived suppressor cells or monocyte-derived dendritic cells), which trigger a particular aspect of acquired immunity, producing different cytokines, and progress to a final phase characterized by proliferation of myofibroblasts and production of strongly pro-fibrotic cytokines (interleukin-4 and interleukin-13). The involvement of innate and acquired immunity in $\mathrm{KD}$ is also confirmed by the presumed association with different genetic polymorphisms in different genes $(I T P K C ; B L K ; F c G R 2 A)$ with regulatory functions [69-78].

\section{Presentation and clinical course of Kawasaki disease General signs and symptoms}

Signs and symptoms useful to the diagnosis of KD are defined "diagnostic clinical criteria" and are represented by: 
- presence of $\geq 5$ days of fever (including cases of therapy-induced defervescence before day 5),

- bilateral non-exudative conjunctivitis,

- erythema of the lips and oral mucosa,

- changes in the extremities,

- skin rash,

- cervical lymphadenopathy [6].

Fever is typically high-spiking and remittent. In the absence of appropriate therapy, fever might persist for a mean of 11 days, but it may continue for 3 to 4 weeks and, rarely, even longer. Bilateral conjunctival injection usually involves the bulbar conjunctivae, sparing the limbus, the avascular zone around the iris; it is usually painless, and appears immediately following the onset of fever. Mild acute iridocyclitis or anterior uveitis may be noted by slit-lamp; it resolves rapidly and rarely is associated with photophobia or eye pain; it is mild, bilateral, and resolves within 2-8 weeks. Changes of the lips and oral cavity include erythema, dryness, fissuring, peeling, cracking, bleeding of lips, "strawberry tongue" with diffuse erythema of the oropharyngeal mucosa. Rash is usually polymorphic and nonspecific: it may show various forms, and the most common is a diffuse maculopapular eruption, appearing in over $90 \%$ of cases, typically within 3-5 days of fever onset. Bullae or vesicles are not seen. Occasionally seen are urticarial exanthema, scarlatiniform rashes, erythroderma, erythema multiform-like rash, micropustular and pustular eruptions [79]. Erythema of the palms and soles may sometimes accompanied by painful induration of both hands or feet. Desquamation of fingers and toes usually begins in the periungueal region within 2 to 3 weeks after the onset of fever and may extend to the palms and soles. Desquamation, usually with a "glove finger" pattern, is not KD-specific, because it might appear in some infectious diseases. Deep transverse grooves across the nails (Beau's lines) may appear approximately 1 to 2 months after the disease onset. In the acute phase, erythema of the perineal region can be observed, where early desquamation may occur: this is a typical sign of $\mathrm{KD}$, recently proposed among the clinical criteria. Cervical lymphadenopathy is the least common of KD principal clinical features, usually unilateral, in the anterior cervical triangle, and involving $\geq 1$ lymph node that is $>1,5 \mathrm{~cm}$ in diameter, firm, non-fluctuant, not associated with marked erythema of the overlying skin, and nonresponsive to antibiotic therapy.

\section{Other clinical findings of Kawasaki disease}

As $\mathrm{KD}$ is an acute systemic vasculitis, which can affect medium-small arteries, more clinical findings can be present (the most frequent are in italic).
- Heart: coronaritis, pericarditis, myocarditis, endocarditis, arrhythmia, mitral regurgitation/aortic and tricuspidal regurgitation (in the acute phase), aortic dilation (in a later phase), cardiac failure, shock.

- Vascular system: Raynaud's phenomenon, peripheral gangrene.

- Joints: arthritis or arthralgia.

- Nervous System: irritability (a particularly suggestive symptom of $\mathrm{KD}$, but not yet considered as pathognomonic), aseptic meningitis, encephalopathy, seizures, ataxia, sensorineural hearing loss, transient unilateral peripheral facial nerve palsy.

- Gastrointestinal tube: diarrhea, vomiting, abdominal pain, acute abdomen, hepatic enlargement and jaundice, acute acalculous distention of the gallbladder (hydrops), acute pancreatitis, cholestatic jaundice, retropharyngeal abscesses are described in $3.6 \%$ of cases [80, 81].

- Urinary system: aseptic pyuria, proteinuria, urethritis, testicular swelling.

- Skin: erythema and induration at the site of a previous bacillus Calmette-Guérin vaccination [82].

- Respiratory system: cough, rhinorrea, slowresolution pneumonia, pulmonary nodules, and lung infiltrates.

\section{Clinical course of Kawasaki disease}

KD clinical course can be divided into three clinical phases: acute, subacute, and convalescence phase (Table 4).

\section{Differential diagnosis of Kawasaki disease}

Table 5 shows the most frequent illnesses to consider in the differential diagnosis with KD, subdivided into infectious and non-infectious. Excluding all possible infectious diseases is recommended. A simultaneous viral or bacterial infection cannot be excluded, and consequently the identification of viral or bacterial agents cannot exclude KD diagnosis and also IVIG treatment. A concomitant bacterial infection must additionally be treated with antibiotics. It is also important to emphasize that a 
Table $\mathbf{5}$ List of illnesses entering in differential diagnosis with Kawasaki disease

\begin{tabular}{ll}
\hline Infectious illnesses & Non-infectious illnesses \\
\hline . viral (rubella, adenovirus, enterovirus, cytomegalovirus, Epstein-Barr virus, parvovirus B19, human herpesvirus 6) & . drug hypersensitivity reaction \\
. scarlet fever & . Stevens-Johnson syndrome \\
. Mycoplasma pneumoniae infection & . juvenile idiopathic arthritis \\
. toxic shock syndrome & . polyarteritis nodosa \\
. staphylococcal scalded skin syndrome & .autoinflammatory syndromes \\
. bartonellosis & sarcoidosis \\
. Rocky mountain spotted fever & . acrodynia \\
. tularemia & \\
. leptospirosis & \\
\hline
\end{tabular}

positive response to IVIG does not automatically confirm diagnosis of $\mathrm{KD}$, as other diseases (e.g. sepsis) can be also treated with this same therapy. Finally, coronary artery dilation is not pathognomonic of $\mathrm{KD}$, and indeed it can be present in the acute febrile phase of both infectious (Epstein-Barr virus infection, and Rocky mountain spotted fever) and inflammatory diseases (systemic onset-juvenile idiopathic arthritis, Takayasu disease, polyarteritis nodosa, and systemic lupus erythematosus) [83-88].

\section{Cardiovascular complications of Kawasaki disease}

The most relevant complications in KD are represented by CAA, and different remodeling phenomena will affect their prognosis. The coronary artery dilation may start as ectasia, slight expansion (up to less than $5 \mathrm{~mm}$ in diameter), moderate dilation (from 5 to less than $8 \mathrm{~mm}$ ) up to giant aneurysms (more than $8 \mathrm{~mm}$ in diameter). The majority of coronary artery aneurysms occur in the proximal segments and at the branch level. KD patients with normal coronary arteries or with mild ectasia at 6 weeks since disease onset have an overall good prognosis $[6,89,90]$. On the contrary, patients with persistent aneurysms are at risk of stenosis and/or thrombosis of the same arteries. Giant coronary aneurysms do not revert to a normal morphology (see Tables 7 and 8 for details). The repair of affected vessels occur by wall remodeling without total "restitutio ad integrum", but with progressive intimal hyperplasia and fibrosis, that lead to stenotic changes of the coronary artery, with risk of thrombosis, myocardial heart attack, and sometimes even sudden death. Rarely new aneurysms appear later in patients with pre-existing aneurysms and, if this occurs, they represent post-stenotic dilations. In rare cases aneurysms can develop in the axillary or celiac arteries. Other different cardiovascular complications may develop less frequently in patients with acute $\mathrm{KD}$, and include myocarditis, pericarditis or pericardial effusion with myopericarditis, valvular insufficiency, and, rarely, arrhythmias. A specific treatment may be required for these manifestations as well as for cardiac dysfunction or heart failure [91, 92] (see part II).

\section{Other complications of Kawasaki disease}

Anemia, hypoalbuminemia, electrolyte imbalance, liver dysfunction, cholecystitis, seizures, diarrhea, vomiting, dehydration, and heart failure might occur and specific treatments may be required. The occurrence of macrophage activation syndrome has also been reported [93-95], while another potential complication is KD shock syndrome [96] (see part II).

\section{Recurrence of Kawasaki disease}

Recurrence of KD ranges from 1.4 to 3\% (respectively from the Chinese and Japanese epidemiologic studies available). Often KD symptoms are the same as for the first episode. A longlasting fever, IVIG resistance, elevated AST levels, reduced hemoglobin are all risk factors related to KD recurrence [97]. A recurring KD is associated with a higher risk of development of CAA. Autoinflammatory syndromes should be considered for a comprehensive differential diagnosis in childhood [98].

\section{Investigations in Kawasaki disease}

Diagnosis of KD is based on the sole clinical diagnostic criteria $[5,6]$, because neither pathognomonic clinical features nor specific diagnostic tests exist. A prompt diagnosis is crucial because prognosis relies on the rapidity of treatment. Consequently, in case of suspected KD, it is important to recommend patient's hospitalization to perform a thorough evaluation and confirm diagnosis. Unfortunately, laboratory tests are nonspecific, though they can support KD diagnosis (see Table 6) $[1,6]$ in patients with suggestive clinical features of KD.

\section{Laboratory findings}

Leukocytosis is typical during the acute phase of this disease with predominance of immature and mature granulocytes. Anemia occurs commonly and is normochromic normocytic: it resolves with the resolution of inflammation. Elevation of acute-phase reactants as ESR and CRP is frequent, but sometimes they are only slightly increased. Moreover, ESR is elevated by IVIG therapy, and therefore, a decreased ESR during follow-up should not be used to assess response to treatment with IVIG. Thrombocytosis is characteristic in the second week of the disease, peaking in the third week and normalizing by 4 to 6 weeks after onset in most cases; thrombocytopenia is rare, but may occur in the first 1 to 2 weeks of illness: thrombocytopenia 
Table 6 Main laboratory abnormalities in patients with Kawasaki disease

\begin{tabular}{ll}
\hline BLOOD CELL COUNT & \\
white blood cells & $\uparrow$, maximal elevation of polymorphonuclear cells \\
& $\downarrow$ rarely \\
red blood cells & $\downarrow$, normal mean corpuscular volume \\
platelets & $\uparrow$, typically in the II and III week, normalization \\
& in $4-8$ weeks \\
& if $\downarrow$ suspect disseminated intravascular \\
& dissemination
\end{tabular}

INFLAMMATORY PARAMETERS

$\begin{array}{ll}\begin{array}{l}\text { erythro-sedimentation } \\ \text { rate (ESR) }\end{array} & \uparrow \text {, slow normalization } \\ \text { C-reactive protein (CRP) } & \uparrow \text {, fast normalization } \\ \text { LIVER FUNCTION TESTS } & \\ \text { transaminases } & \uparrow \\ \text { bilirubinemia } & \uparrow \\ \text { gamma-glutamyl } & \uparrow \\ \text { transpeptidase } & \text { more severe and prolonged illness if } \downarrow \\ \text { albuminemia } & \text { white blood cells }>\text { 10/high field powered } \\ \text { OTHER LABORATORY TESTS } \\ \begin{array}{ll}\text { urine } & \text { aseptic meningitis (presence of mononuclear } \\ \text { cerebrospinal fluid } & \text { cells, normal glucose/proteins) } \\ & \text { purulent-appearing fluid, white blood cells } \\ \text { synovial fluid } & 125.000-300.000 / \mathrm{mm}^{3} \text {, normal glucose level }\end{array} \\ \end{array}$

can be a sign of disseminated intravascular coagulation and is a risk factor for the development of coronary artery abnormalities. In patients with arthritis, arthrocentesis typically yields purulent-appearing fluid with a white blood cell count of 125,000 to 300,000 per $\mathrm{mm}^{3}$, a normal glucose level and negative culture tests. Mild to moderate elevations in serum transaminases or gamma-glutamyl transpeptidase occur in 40 to $60 \%$ of patients, and mild hyperbilirubinemia occurs in $10 \%$. Hypoalbuminemia is common and associated with more severe and more prolonged acute disease. Urinalysis may show pyuria in up to $80 \%$ of children. In children who undergo lumbar puncture, $30 \%$ demonstrate pleiocytosis with a mononuclear cell predominance, normal glucose levels and generally normal protein levels.

Recommendation 5 Laboratory data are nonspecific in $\mathrm{KD}$ and can only support diagnosis in patients with suggestive clinical features.

$(\mathrm{V}-\mathrm{B})$

\section{Dyslipidemia and risk of atherogenesis in patients with Kawasaki disease}

A disrupted lipid metabolism may characterize the acute phase of KD, and finally give a reduction of serum total cholesterol, particularly HDL, and increase of triglyceridemia. Some studies have reported that this altered lipid state might persist over a period of 3 years after KD diagnosis. The effect of dyslipidemia on the cardiovascular risk is not completely clear: while some studies proved early ultrasound signs of reduced elasticity and abnormal carotid intima-media thickness in young adults with history of $\mathrm{KD}$, subsequent studies were not confirmatory [99-102]. The presence of CAA seems also to correlate more significantly with lipid metabolism disorders, whereas this finding remains controversial in patients without CAA [103].

\section{Pro-inflammatory conditions and pro-coagulant activity of the peripheral blood in patients with Kawasaki disease}

The formation of reactive oxygen and nitrogen species in $\mathrm{KD}$ is known to generate a systemic pro-oxidant status in the blood, which might lead to altered red blood cell and platelet homeostasis with propensity to develop a cascade of procoagulant complications and focal endothelial damage [104-106]. Particularly, inflammation associated with systemic pro-oxidant state can play a key role in the pathogenesis and progression of KD. Reactive oxygen and nitrogen species (collectively called RONS) generate a pro-oxidant status in the blood that promote an oxidative and nitrative stress as well as a redox imbalance, leading to altered cell signaling and functions. Whole blood from patients with KD show increased levels of RONS, while scavenger activity of RONS might be significantly decreased during the acute phase of KD. Finally, thrombocytosis might result from a defect of cell death, as suggested by studies about annexin $\mathrm{V}$ positive and negative platelets, and the propensity to develop coronary damage may be associated with altered platelet homeostasis [104-106].

\section{Echocardiography}

Echocardiography should be performed by a cardiologist with experience in the pediatric age, and the coronary artery districts to visualize include left coronary artery, descending coronary artery, circumflex artery, left anterior artery, right coronary artery, and posterior descending coronary artery. The presence of marked perivascular brightness, the absence of the physiological gradual reduction of coronary artery caliber, and a mild ectasia, if isolated, are not indicative of $\mathrm{KD}$; however, these findings could be considered a positive echocardiographic sign when they are all three simultaneously present (expert opinion) to suggest KD diagnosis. Changes in the left ventricular function, presence of mild mitral or aortic regurgitation, and pericardial effusion may be present in the KD acute phase, though they should not be considered sufficient for confirming KD diagnosis [111]. Stenosis and thrombosis might appear in later phases and/or in older 
patients, when the coronary arteries are more difficult to see on routine ultrasound investigations. Stress echo with the administration of drugs (dobutamine) is now widely used for the diagnosis and follow-up of secondary ischemic heart disease in patients with KD $[112,113]$.

Recommendation 6 Bidimensional and color-Doppler echocardiography and/or associated techniques (tissueDoppler imaging, 3D echocardiography imaging) are pivotal modalities to perform cardiac assessment of patients with $\mathrm{KD}$, as they are non-invasive repeatable investigations, characterized by both high sensitivity and high specificity.

$(\mathrm{V}-\mathrm{A})$

Criteria for the recognition of KD-related CAA have been defined by the Japanese Ministry of Health, based on the absolute values of coronary arteries size among patients of different age groups [107]. However, in cases that did not meet these criteria it was reported an increased incidence of CAA at different phases of the disease, compared to patients belonging to homogeneous and comparable groups for age and body surface area [108].

The concept of z-score was introduced several years ago to compare the coronary artery diameter to the body surface area and measure the standard deviation from the average in $\mathrm{Z}$ units (SD, $\mathrm{z}$-score), using specific nomograms (www.parameterZ.com). This is recommended for the right coronary, left anterior descending, left main coronary arteries, and also for other vascular structures such as the aortic ring and ascending aorta. We define a $\mathrm{z}$-score $<2.5$ normal, viceversa pathological if $\geq 2.5$, with features of "ectasia" or "aneurysm" depending on the morphological characteristics observed. This standard deviation system should be used in the initial diagnosis of CAA when there is a suspicion of KD, when the selection may be more "coarse" to avoid losing patients that may be at risk in the near future; conversely, size criteria should be used in the follow-up of KD patients, particularly if localized coronary artery injuries have been found (see Table 7) $[1,109,110]$.

The severity of Kawasaki disease is classified into the following 5 grades on the basis of findings of echocardiography and selective coronary angiography or other methods (see Table 8) [110].

In up to $80 \%$ of patients with significant dilation or aneurysms at later echocardiograms some abnormality is evident on the initial echocardiogram obtained in the first 10 days of illness [1]. The largest proportion of patients with coronary artery abnormalities will have dilation only, characterized by luminal measurements outside the normal range, but with a maximal $z$-score $<2.5$. Dilation resolves within 4 to 8 weeks in most cases..

Recommendation 7 Echocardiogram must be performed in all patients with a diagnosis of $\mathrm{KD}$; then after 2 ,
Table 7 Classification of coronary artery aneurysms in the acute phase of Kawasaki disease and severity classification

Dilation: diameter $\geq 2.5 \mathrm{SD}$

Small aneurysm:

localized dilation showing an inner diameter $\leq 4 \mathrm{~mm}$ (in children

$\geq 5$ years: the internal diameter of a segment $<1.5$ times compared to an adjacent segment)

Z-Score $\geq 2.5$ to $<5$

Medium aneurysm:

aneurysm showing an inner diameter $>4 \mathrm{~mm}$ and $<8 \mathrm{~mm}$ (in children $\geq 5$ years: the internal diameter of a segment $1.5 \sim 4$ times compared to an adjacent segment)

z-score $\geq 5$ to $<10$

Giant aneurysm:

aneurysm showing an internal diameter $\geq 8 \mathrm{~mm}$ (in children $\geq 5$ years: the internal diameter of a segment $>4$ times compared to an adjacent segment)

z-score $\geq 10$

4, and 8 weeks since KD onset in the uncomplicated cases, as CAA can be detected in the subsequent weeks after diagnosis.

(VI - B)

Recommendation 8 Persistently febrile non-responders KD patients with CAA, impaired left ventricular function, mild/moderate mitral regurgitation or significant pericardial effusion need a more frequent echocardiogram check-up (at least twice per week).

(VI - A)

The presence of marked perivascular brightness, the absence of the physiological gradual reduction of coronary artery caliber and mild ectasia, if isolated, are not indicative of KD. These findings could be considered a positive echocardiographic KD sign when they are all three simultaneously present (expert opinion). Changes

Table 8 Severity classification of coronary artery aneurysms in Kawasaki disease

I. No coronary dilatation: patients with no coronary dilatation including those in the acute phase

II. Transient coronary dilatation during the acute phase: patients with slight and transient coronary dilatation which typically subsides within 30 days after onset

III. Regression: patients who still exhibit coronary aneurysms meeting the criteria for dilatation or more severe change on day 30 after onset, despite complete disappearance of changes in the bilateral coronary artery systems during the first year after onset, and who do not meet the criteria for Group V

IV. Remaining coronary aneurysm: patients in whom unilateral or bilateral coronary aneurysms are detected by coronary angiography in the second year or later and who do not meet the criteria for Group V

V. Coronary stenotic lesions: patients with coronary stenotic lesions detectable by coronary angiography

(a) Patients without ischemic findings: patients without ischemic signs/symptoms detectable by laboratory tests or other examinations

(b) Patients with ischemic findings: patients with ischemic signs/ symptoms detectable by laboratory tests or other examinations 
in left ventricular function, presence of mild mitral or aortic regurgitation, pericardial effusion may be present in the KD acute stages but should not be considered sufficient for the diagnosis, as they can also be found in other inflammatory disease.

Moreover, pericarditis, mitral insufficiency, impairment of systolic function, indirect signs of inflammation, can be predictive of coronary lesions, which could be non permanent. Actually echocardiographic sensibility and specificity is not so clear in diagnosis of stenosis and thrombi.

These lesions appear usually in later phases and in older patients, when coronary arteries system is more difficult to see.

Echocardiography remains the instrument of choice to identify CAA during the acute phase of $\mathrm{KD}$ up to the first 6 weeks after onset. However, computed tomography $(\mathrm{CT})$ or magnetic resonance (MR) angiography can be required for an accurate risk stratification via evaluation of the vascular system, especially in growing children. Advanced cardiovascular imaging techniques for a more specific assessment of cardiovascular sequelae in $\mathrm{KD}$ are CT and MR angiography. Multi-slice CT is an established tool for a less-invasive assessment of the cardiovascular system in adults: the diffusion of such a technique for coronary artery studies in children with KD is still limited. This is mainly due to radiation exposure issues, need for general anesthesia, need for beta-blockers (to obtain regular heart rates ideally lower than 65-70 beats per minute), and enhancement contrast infusion. A dual-source CT (DSCT) provides excellent quality images and low radiation doses for diagnosing KD-related CAA in infants and children [114]. Moreover, DSCT is superior to echocardiography in the detection of CAA located in the peripheral parts of vessels [115]. New generation scanners enable a very rapid body CT scan (less than $1 \mathrm{~s}$ ), permit central/peripheral aneurysm detection, and reduce the need for general anesthesia [116]. The majority of magnetic resonance (MR) angiography studies on KD have been performed using 1.5 Tesla magnets fully equipped for cardiac investigation with a set up for general anesthetic support, using a comprehensive scan protocol which includes functional imaging with breath-hold, ECG-gated, 2D steady-state free precession, contrast-enhanced study for whole body detection of central and peripheral aneurysmal dilations during intravenous infusion of contrast (gadolinium at a dose of $0.1 \mathrm{mmol} / \mathrm{kg}$ of body weight), or myocardial perfusion imaging at rest and after pharmacological stress [117-119]. Advanced imaging studies with cardiovascular CT or MR may be reasonable in selected patients to help in the management decisions, as cardiac catheterization in the acute phase of KD has been associated with a greater incidence of adverse vascular events [1]. Conversely, there are limited data regarding cardiac function after the acute phase of KD. Subclinical dysfunctions may be missed when assessing left ventricular systolic function using conventional echocardiography. Recently, speckle-tracking echocardiography is emerging as an effective tool for determining global longitudinal and circumferential strain and myocardial deformation in patients with KD, especially in mid-long term follow-up [120].

Recommendation 9 Cardiovascular CT scan, ideally with a DSCT scanner, should be used in patients with KD to:

- confirm CAA (and rule out false positive cases due to coronary artery anomalies or anatomical variants)

- detect middle-distal CAA (not usually seen at routine echocardiograms)

- more accurately define caliber and morphology of CAA

- identify coronary artery thrombosis or occlusions

- evaluate other aneurysms, both central or peripheral, in the entire body

- reveal myocardial ischemia or reassess caliber and morphology of CAAs and better define their treatment. (VI - C)

Cardiovascular CT scan in the further follow-up phases can be used to monitor the results of previously treated coronary arteries (e.g., after stenting) (see Part II for details).

Recommendation 10 Cardiovascular MR angiography should be used in patients over 8 years with KD to:

- confirm CAA (and rule out false positive cases due to coronary artery anomalies or anatomical variants).

- identify other aneurysmal dilations, either central or peripheral, in the vascular system.

- assess biventricular global/regional systolic function.

- depict any myocardial scar with contrast-enhancement and visualize gross coronary artery anatomy.

(VI - C)

In the further follow-up phases cardiovascular MR angiography can be used to detect areas of inducible myocardial ischemia during pharmacological stress (e.g., adenosine stress perfusion test) (see Part II for details).

\section{Treatment of Kawasaki disease}

In this first part of the Guidelines the only treatment of the acute phase will be discussed.

\section{Treatment of the acute phase of Kawasaki disease}

The main goal of treatment in the acute phase of KD is suppressing the inflammatory reaction and minimizing the risk of developing CAA. A host of data about the 
administration of intravenous immunoglobulin (IVIG) as initial "first-line" treatment in children with KD has confirmed the efficacy and safety of this therapy. In fact, following IVIG introduction since the early 1980s, the overall incidence of CAA is gradually decreased [121]. IVIG should be started before the 7th day of illness: in fact, histological studies have shown that KD arteritis typically develops around the 8-9th day after disease onset. In about $80 \%$ of cases, defervescence occurs within $48 \mathrm{~h}$ after IVIG infusion.A persistent or reoccurring fever after $48 \mathrm{~h}$ since a first administration of IVIG configures the framework of IVIG-resistant KD (approximately $15-20 \%$ of patients). Nowadays there is no still effective and universally accepted treatment for these patients, and therefore treatment of these challenging patients will have to be cut out ad hoc. In addition, there is no universally accepted classification system for evaluating the severity of KD or possibility to modulate therapy: many scoring systems have been proposed, but they have shown little sensitivity in the Western populations than in Japanese one [122].

The initial treatment of KD acute phase includes the combined use of IVIG and aspirin (acetylsalicylic acid, ASA).

\section{Intravenous immunoglobulin (IVIG) \\ Rational}

High-dose IVIG is the most effective anti-inflammatory treatment to reduce the risk of CAA in patients with KD [123-126], as confirmed by a systematic Cochrane review [127]. IVIG is derived from human plasma and requires an informed consent before use.

\section{Mechanism of action}

Since KD causes are unknown, the mechanisms of action of IVIG remain speculative. The hypothesized action mechanisms mainly are anti-inflammatory and mediated by the Fc receptor, $\mathrm{B}$ and $\mathrm{T}$ cells, and dendritic cells [128-131].

\section{Therapeutic indication}

IVIG is indicated in the acute phase of typical, incomplete and atypical KD; IVIG should not be administered if fever spontaneously disappears, if CAA are not shown, or if inflammatory markers (ESR and CRP) are within normal limits.

\section{Dosage}

A dose of $2 \mathrm{~g} / \mathrm{kg}$ of body weight in a single infusion significantly reduces the incidence of CAA, and is able to suppress both inflammation and fever. The rate of infusion of IVIG varies slightly for different products, though IVIG is usually administered in $12 \mathrm{~h}$ in North America and in $24 \mathrm{~h}$ in Japan. Currently there is no apparent difference for efficacy among different brands of IVIG.Close monitoring and reduced rate of infusion are necessary during the first $30-60 \mathrm{~min}$ in order to reduce the risk of anaphylaxis. During the administration of IVIG, presence of fever or a further rise in temperature do not contraindicate the administration which should not be withdrawn. IVIG should be started within 7 days since KD onset to rapidly reduce inflammation, as in the 8-9th day CAA might appear. One study compared patients treated with IVIG within the 5th day of illness with those who received IVIG between the 6th and 9th day: the groups did not differ in the incidence of resistance to therapy or number of days of hospitalization, though 1 year later those who received IVIG earlier had a lower incidence of coronary artery disease [132]. In addition, we must consider that KD enters a differential diagnosis with many diseases, therefore treatment of suspected cases before the 5 th day of fever could intercept patients with other diagnoses. Furthermore, the administration of IVIG is expensive and might be related to even severe, although infrequent, side effects. Treatment before the 5th day of fever should be reserved to exceptional cases of unequivocal diagnosis of KD [133].

\section{Effectiveness}

IVIG is quite safe and, at present, are the most effective therapy in KD.

\section{Side effects}

The donated blood is carefully screened to confirm the absence of HBsAg, anti-HCV antibodies, anti-HIV-1/2 and anti-HTLV-1 antibodies, and to verify the absence of nucleic acid from HIV, hepatitis B virus, hepatitis C virus, hepatitis A virus, and human parvovirus B19. Using the existing pharmaceutical production processes, the absence of viruses cannot be determined with $100 \%$ certainty, but there have been no reports of viral infections caused by IVIG infusion. Therefore, side effects are rare, and include chills, hypotension, anaphylactic reactions, aseptic meningitis, hemolytic anemia, abnormal liver function tests, jaundice, acute renal failure, thrombocytopenia, and pulmonary edema. Patients should be closely monitored, particularly immediately after the start of IVIG infusion and when increasing the infusion rate. Patients may also develop cardiac dysfunction or acute heart failure, and therefore it is necessary to prevent a sudden increase of circulating blood volume. When using IVIG, it is necessary to consider allergic reactions in response to IVIG in patients with IgA deficiency, the risk of a further deterioration of renal function in patients with a previous kidney damage, thromboembolic events such as cerebral infarction or myocardial infarction in patients with previous or present cardiovascular or cerebral damage [134, 135]. 
Recommendation 11 IVIG must be administered at dose $2 \mathrm{~g} / \mathrm{kg}$ of body weight in a single infusion, within the first 7th day of illness, anyway within the 10th day. Administration should be performed in $12 \mathrm{~h}$ if patient's cardiac function is normal, or in 16-24 h for patients displaying cardiac failure.

$$
\text { (I - A) }
$$

Recommendation 12 IVIG should also be administered to children presenting after the 10th day of illness in case of:

- persistent fever

- no more fever but aneurysms and ongoing systemic inflammation, as shown by elevation of CRP.

$$
(\mathrm{V}-\mathrm{B})
$$

\section{Aspirin (acetylsalicylic acid, ASA) Rational}

The mechanism of action of aspirin differs according to the dosage: medium-high dosages are used for the anti-inflammatory effect in the acute febrile phase of $\mathrm{KD}$, while lower dosages are used for the antiplatelet effect in the subacute phase, when the risk of CAA is higher.

\section{Mechanism of action}

ASA blocks the synthesis of prostaglandin E2 from arachidonic acid, thereby exerts its anti-inflammatory effect, but also inhibits platelet aggregation by blocking the synthesis of thromboxane A2 by cyclooxygenase.

\section{Indications}

ASA is approved for all patients with KD.

\section{Dosage}

Associated with IVIG in the initial treatment, ASA anti-inflammatory dosage varies from 80 to $100 \mathrm{mg} / \mathrm{kg} /$ day in the USA to $30-50 \mathrm{mg} / \mathrm{kg} /$ day in Japan, subdivided into four doses [136]. Then, $48 \mathrm{~h}$ after defervescence, aspirin can be used at an antiplatelet dosage: $3-5 \mathrm{mg} /$ $\mathrm{kg} /$ day. The duration of treatment is $6-8$ weeks in KD patients without CAA. However, in patients with CAA, antiplatelet therapy is continued until resolution of the lesions or indefinitely in case of persistence.

\section{Effectiveness}

Many studies do not demonstrate that the anti-inflammatory effect of aspirin reduces the development of CAA; furthermore, recent studies suggest to start immediately with an antiplatelet dosage in the acute phase of $\mathrm{KD}$, in consideration of the procoagulant state of platelets in $\mathrm{KD}[137,138]$.

\section{Side effects}

The use of ASA at medium-high dosage can be associated with risk of hemorrhage, asthma, liver failure, gastrointestinal ulcers, hives, rash, kidney failure, and loss of appetite. Liver failure is frequent, therefore assessment of transaminase level is mandatory; in case of changes it is necessary to reduce ASA dosage or stop treatment. In case of chickenpox (varicella) and flu the possibility of Reye's syndrome should be considered, while at low dosage of ASA the occurrence of this syndrome is rare.

Recommendation 13 In the KD acute phase ASA must be administered at a daily dosage of $30-50 \mathrm{mg} / \mathrm{kg}$ divided into 4 doses until $48 \mathrm{~h}$ after disappearance of fever.

$$
(\mathrm{I}-\mathrm{A})
$$

Recommendation 14 When high-dose ASA is discontinued, low-dose ASA (3-to- $5 \mathrm{mg} / \mathrm{kg}$ per day) must be started.

(I- A)

In the medical literature there is an ongoing debate about discontinuation of aspirin depending on the size of CAA.

Recommendation 15 In patients without CAA low-dose ASA is to be discontinued 8 weeks after KD onset. In children who develop CAA low-dose ASA may be continued until the resolution of vascular lesions or indefinitely in case of its persistence.

(V - B)

Attempting to identify which KD patients should be unresponsive to treatment with IVIG or predicting the ones who might display a significant risk of developing cardiologic sequels are two issues of outstanding priority. Many efforts have been made to discriminate as soon as possible the cohort of IVIG nonresponder patients in order to undertake a more aggressive treatment since KD onset: different scores have considered multiple factors, such as patient's age, sex, duration of disease, white blood cell count, hematocrit, platelet count, C-reactive protein, transaminases, total bilirubin, albumin, sodium, however none of them has shown high sensitivity in Caucasian populations [139].

High-risk KD patients are younger than 12 months, show elevated CRP, elevated aminotransferase level, hypoalbuminemia, severe anemia at disease onset and might display early development of CAA, signs of macrophage activation syndrome or shock.

Recommendation 16 High-risk KD patients should receive initial therapy with IVIG + ASA + corticosteroid (1 pulse of intravenous methylprednisolone: $30 \mathrm{mg} / \mathrm{kg} /$ 
day as a single administration or intravenous prednisone: $2 \mathrm{mg} / \mathrm{kg} /$ day, then tapered orally).

$$
\text { (I - B) }
$$

\section{Vaccines: The potential interactions with IVIG and ASA}

The analysis of KD cases reported by the Vaccine Adverse Event Reporting System (VAERS) of USA up to 2007 showed that the incidence of this disease in children who received all registered vaccines was similar or even less than the incidence expected on the basis of the known epidemiology of KD in Italy. On the contrary, the administration of vaccines is associated with a lower frequency of occurrence of KD at least for the 42 days following vaccine administration without differences among the various preparations [140]. A recent study, reporting data of 1.721 .186 children between 0 and 6 years old, followed by a long period of time, shows that in KD patients the frequency of administration of vaccines in the 42 days preceding the onset of the syndrome was lower than controls non-vaccinated [141].

KD treatment with IVIG does not significantly interfere with all inactivated vaccines, oral attenuated live virus vaccines (rotavirus, typhoid vaccination), live virus nasal vaccines (flu), bacillus Calmette-Guérin (BCG) vaccine, and yellow fever vaccine. Consequently, these vaccines can be administered concurrently with the administration of IVIG or at any time after administration of IVIG in KD. It is usually recommended to wait 10 months before administration of vaccine against measles, mumps, rubella (MMR), varicella (V), and MMRV vaccines, as this could interfere with the immune response to MMR, V and MPRV antigens, which may result in a reduced immunogenicity [142].

In KD patients who are receiving ASA flu vaccination is strongly recommended for the known relationship between the influenza virus infection and the development of Reye's syndrome in children and adolescents treated with salicylates [143]; for the same reason it is discussed about the administration of $\mathrm{V}$ vaccine in children with KD on ASA prophylaxis. Pharmaceutical companies producing vaccines containing $\mathrm{V}$ (as a monovalent preparation or as MPRV formulation) indicate on the package that subjects who receive salicylates should discontinue these medications for 6 weeks following the administration of this vaccine [144]. This attitude is not shared by several scientific authorities for the lack of data indicating an actual risk of the vaccine in these patients. Some experts suggest deciding whether or not to vaccinate against chickenpox based on an accurate assessment of the risk of vaccination and those of the disease in the individual patient. If you decide to vaccinate $\mathrm{KD}$ children on ASA with V or MPRV vaccines, ASA might be replaced by clopidogrel: its dosage is $1 \mathrm{mg} / \mathrm{kg} /$ day in a single dose (up to a maximum of $75 \mathrm{mg} /$ day in children
$>2$ years, or $0.2 \mathrm{mg} / \mathrm{kg}$ of body weight in children $<24$ months). Vaccination against V or MPRV could be given after $48 \mathrm{~h}$ of stopping ASA, and ASA should be restarted by suspending clopidogrel 6 weeks after vaccination [145]. If a $\mathrm{KD}$ patient requires treatment with biologic drugs, it should be assumed that there may be problems of reduced immunogenicity and safety of vaccines [146-149]. As for the live-virus attenuated vaccines, even if there is no evidence of adverse events in the few studies available, it is believed that further studies are needed to confirm their safety; therefore, it is important that the patient receives two doses of MMR vaccine and is adequately protected even against varicella in case of no history of a natural disease for at least 1 month before the start of biological drugs [150].

Recommendation 17 As the administration of every type of vaccine does not increase the risk of reappearance of $\mathrm{KD}$, vaccinations are to be administered in $\mathrm{KD}$ patients.

$$
\text { (III - A) }
$$

Recommendation 18 All inactivated vaccines, rotavirus, oral typhoid, intranasal anti-flu, BCG vaccines and the vaccine against yellow fever may be administered concurrently with the administration of IVIG or at any time after administration of IVIG in KD patients.

$(\mathrm{V}-\mathrm{A})$

Recommendation 19 The MMR, V and MPRV vaccines should be administered 10 months after the administration of IVIG in KD patients to avoid a reduced immune response as result of the specific high antibody titer against the antigens contained in IVIG.

(VI - B)

Recommendation 20 Influenza vaccination is highly recommended in KD patients assuming ASA due to the increased risk of Reye's syndrome.

$$
\text { (III - A) }
$$

Recommendation 21 If a KD patient assuming ASA has to be vaccinated with V or MPRV vaccines, ASA can be replaced by clopidogrel because of a theoretical risk of Reye's syndrome associated with the attenuated varicella-zoster virus contained in these vaccines. Its dosage is $1 \mathrm{mg} / \mathrm{kg} /$ day in a daily administration, up to a maximum $75 \mathrm{mg} /$ day (adult dose), or $0.2 \mathrm{mg} / \mathrm{kg}$ of body weight in children $<24$ months. Additionally, $\mathrm{V}$ or MPRV vaccination can be given after $48 \mathrm{~h}$ of stopping ASA, and ASA can be restarted after suspending clopidogrel 6 weeks after vaccination.

(VI - C) 
Recommendation 22 It is recommended to administer all inactivated vaccines following the routine schedule in patients with KD receiving biological drugs.

$(\mathrm{V}-\mathrm{B})$

Recommendation 23 Attenuated live virus vaccines should be administered 1 month before beginning therapy with biologics in patients with KD, but they are not recommended during treatment with biologics.

(VI - C)

\section{Discussion}

Not applicable.

\section{Conclusion}

Goal of these guidelines is to recommend the best practice in both diagnosis and management of children with KD, based on the most actual scientific evidence, and improve the overall prognosis of this disease. In this first part of guidelines we carried out hypothesis about etiology of KD, because the identification of its etiopathogenic mechanisms would be essential to develop preventive and focused therapeutic strategies. We improved definition of incomplete and atypical KD, avoiding the loss of potential patients. We tried also to evaluate as dyslipidemia, proinflammatory conditions and procoagulant activity might act as cardiovascular risk factors in KD. Concerning instrumental techniques, we strongly emphasized the suggestion of implementing the use of standard deviation system of z-score in echocardiography, to avoid losing patients during the acute phase of KD. We explained other advanced cardiovascular imaging techniques, i.e. computed tomography (CT) or magnetic resonance (MR) angiography, which can be required for an accurate risk stratification of the vascular system. Concerning therapies, we revised timing if IVIG infusion as well as dosages of aspirin. Attempting to identify which KD patients should be unresponsive to treatment with IVIG or predicting the ones who might display cardiologic sequels, we introduced a stratification in low and high-risk patients with different therapeutic indications. Finally we investigated the potential interactions between vaccines and both IVIG and ASA.

\footnotetext{
Abbreviation

ASA: Acetylsalicylic acid; BCG: Bacillus Calmette-Guérin; CAA: Coronary artery aneurysms; CRP: C-reactive protein; CT: Computed tomography; ESR: Erythrocyte sedimentation rate; HbsAg: Hepatitis B surface antigen; HCV: Hepatitis C virus; HIV: Human Immunodeficiency virus; HTLV-1: Human T-cell leukemia virus type 1; IVIG: Intravenous immunoglobulin; KD: Kawasaki disease; MMR: Measles, mumps, rubella; MMRV: Measles, mumps, rubella, varicella; MR: Magnetic resonance; V: Varicella
}

\section{Acknowledgements}

We would like to thanks also Prof. Alessio Maria (Università degli Studi di Napoli Federico II), Dott.ssa Boccaletti Valeria (Azienda OspedalieroUniversitaria di Parma), Dott.ssa Neri Iria (Policlinico S.Orsola-Malpighi,
Bologna), Dott,ssa Granato Carmen (Università degli Studi di Napoli Federico II), Dott.ssa Marotta Rosaria (Università degli Studi di Napoli Federico II).

Funding

No person who participated in the drafting of these guidelines has been sponsored.

Availability of data and materials

No datasets were generated or analyzed during the current study.

\section{Authors' contributions}

AM, ITDJ, DR, AR, GC, and AV: conception and design of the guidelines, collection of in-depth analyses performed by each coauthor, critical revision, manuscript writing and final approval of the manuscript. Coauthors: GB participated in writing the chapter about high risk patients' therapy, SB analyzed data related to dyslipidemia and risk of atherogenesis, FC produced the chapter about epidemiology, EC participated in writing the chapter about presentation and clinical course, FD participated in writing the chapter about high risk patients' therapy, AD studied application and limits of the echocardiography in KD, MD participated in writing the chapter about immunoglobulin therapy, DDP analyzed and synthetized the possible etiopathogenic pathways, RMD worked about the non-cardiovascular complications and follow-up, LD participated in writing the chapter about presentation and clinical course, MEH participated in writing the chapter about presentation and clinical course, SE processed the vaccinations' recommendations, FF participated in writing the chapter about presentation and clinical course, UG processed the sport activity recommendation, MCM participated in writing the chapter about high risk patients' therapy, SM participated in the chapter about echocardiography, GLM participated in the chapter about presentation and clinical course, SM participated in writing the chapter about presentation and clinical course, especially about recurrent forms, GM co- produced the chapter about epidemiology, RM and CP helped us in making the document accessible to KD families, DP analyzed and synthetized proinflammatory conditions and procoagulant activity in KD, MCP worked about patients' follow-up, PS worked about patients' follow-up, AS produced the chapter about instrumental investigations in KD, ES analyzed and synthetized proinflammatory conditions and procoagulant activity in KD, All authors read and approved the final manuscript.

Ethics approval and consent to participate Not applicable.

Consent for publication

Not applicable.

Competing interests

The authors declare that they have no competing interests.

\section{Publisher's Note}

Springer Nature remains neutral with regard to jurisdictional claims in published maps and institutional affiliations.

\section{Author details}

${ }^{1}$ Bambino Gesù Children's Hospital, Rome, Italy, Piazza S. Onofrio n. 4, 00165 Rome, Italy. ${ }^{2}$ Fondazione Policlinico Universitario A. Gemelli, Università Cattolica Sacro Cuore, Rome, Italy. ${ }^{3}$ Giannina Gaslini Institute, Genoa, Italy. ${ }^{4}$ Istituto Superiore di Sanità, Rome, Italy. ${ }^{5}$ Università degli Studi di Palermo, Palermo, Italy. ${ }^{6}$ Università degli Studi di Pavia, Pavia, Italy. ${ }^{7}$ Policlinic Giovanni XXIII, Bari, Italy. ${ }^{8}$ ASL Umbria 2, Foligno, Italy. ${ }^{9}$ Università degli Studi Sapienza, Rome, Italy. ${ }^{10}$ Università degli Studi Tor Vergata, Rome, Italy. ${ }^{11}$ Ospedale Maggiore Policlinico, Milan, Italy. ${ }^{12}$ Ospedale di Battipaglia, Salerno, Italy.

${ }^{13}$ Università degli Studi di Perugia, Perugia, Italy. ${ }^{14}$ University of Florence, Florence, Italy. ${ }^{15}$ Università degli Studi di Torino, Turin, Italy. ${ }^{16}$ Associazione Rari ma Speciali, Rome, Italy.

Received: 23 August 2017 Accepted: 3 May 2018

Published online: 30 August 2018

References

1. McCrindlle BW, Rowley AH, Newburger JW, Burns JC, Bolger AF, Gewitz M, et al. Diagnosis, treatment, and long-term Management of Kawasaki 
Disease, a scientific statement for health professionals from the American heart. Circulation. 2017;135:e927-99.

2. Jennette JC, Falk RJ, Bacon PA, Basu N, Cid MC, Ferrario F, et al. 2012 revised international Chapel Hill consensus conference nomenclature of Vasculitides. Arthritis Rheum. 2013;65:1-11.

3. Kawasaki T. Acute febrile mucocutaneus syndrome with lymphoid involvement with specific desquamation of the finger and toes in children. Arerugi. 1967;16:178-222.

4. Kato H, Sugimura T, Akagi T, Sato N, Hashino K, Maeno Y, et al. Long-term consequences of Kawasaki disease. A 10- to 21-year follow-up study of 594 patients. Circulation. 1996;94:1379-85.

5. Dajani AS, Taubert KA, Gerber MA, Shulman ST, Ferrieri P, Freed M, et al. Diagnosis and therapy of Kawasaki disease in children. Circulation. 1993;87:1776-80.

6. Newburger JW, Takahashi M, Gerber MA, Gewitz MH, Tani LY, Burns JC, et al. Diagnosis, treatment, and long-term management in Kawasaki disease: a statement for health professionals from the committee on rheumatic fever, endocarditis and Kawasaki disease, council on cardiovascular disease in the young. Am Heart Assoc Pediatrics. 2004;114:1708-33.

7. Uehara R, Belay ED. Epidemiology of Kawasaki disease in Asia, Europe, and the United States. J Epidemiol. 2012;22:79-85.

8. Kim GB, Han JW, Park YW, Song MS, Hong YM, Cha SH, et al. Epidemiologic features of Kawasaki disease in South Korea: data from nationwide survey, 2009-2011. Pediatr Infect Dis J. 2014;33:24-7.

9. Saundankar J, Yim D, Itotoh B, Payne R, Maslin K, Jape G, et al. The epidemiology and clinical features of Kawasaki disease in Australia. Pediatrics. 2014;133:e1009-14.

10. Bar-Meir M, Haklai Z, Dor M. Kawasaki disease in Israel. Pediatr Infect Dis J. 2011;30:589-92.

11. Singh S, Vignesh P, Burgner D. The epidemiology of Kawasaki disease: a global update. Arch Dis Child. 2015;100:1084-8.

12. Tamburlini G, Strinati R, Cadorini S, Calligaris A, Coprivez A, Cozzi M, et al. A two-year survey of mucocutaneous lymph node syndrome in north-eastern Italy. Epidemiological and clinical findings. Helv Paediatr Acta. 1984;39:319-29.

13. Makino N, Nakamura Y, Yashiro M, Ae R, Tsuboi S, Aoyama Y, et al. Descriptive epidemiology of Kawasaki disease in Japan, 2011-2012: from the results of the 22nd nationwide survey. J Epidemiol. 2015;25:239-24.

14. Falcini F, Capannini S, Rigante D. Kawasaki syndrome: an intriguing disease with numerous unsolved dilemmas. Pediatr Rheumatol. 2011;9:17.

15. De Rosa G, Pardeo M, Rigante D. Current recommendations for the pharmacologic therapy in Kawasaki syndrome and management of its cardiovascular complications. Eur Rev Med Pharmacol Sci. 2007;11:301-8.

16. Harnden A, Alves B, Sheikh A. Rising incidence of Kawasaki disease in England: analysis of hospital admission data. BMJ. 2002;324(7351):1424-5.

17. Lue HC, Chen LR, Lin MT, Chang LY, Wang JK, Lee CY, et al. Epidemiological features of Kawasaki disease in Taiwan, 1976-2007: results of five nationwide questionnaire hospital surveys. Pediatr Neonatol. 2014;55:92-6.

18. Kang HJ, Kim GN, Kil HR. Changes of clinical characteristics and outcomes in patients with Kawasaki disease over the past 7 years in a single center study. Kor J Pediatr. 2013;56:389-95.

19. Callinan LS, Tabnak F, Holman RC, Maddox RA, Kim JJ, Schonberger LB, et al. Kawasaki syndrome and factors associated with coronary artery abnormalities in California. Pediatr Infect Dis J. 2012;31:894-8.

20. Ruan $Y, Y e$ B, Zhao X. Clinical characteristics of Kawasaki syndrome and the risk factors for coronary artery lesions in China. Pediatr Infect Dis J. 2013;32:e397-402

21. Burns JC, Herzog L, Fabri O, Tremoulet AH, Rodó X, Uehara R, et al. Seasonality of Kawasaki disease: a global perspective. PLoS One. 2013;8:e74529.

22. Rodó X, Curcoll R, Robinson M, Ballester J, Burns JC, Cayan DR, et al. Tropospheric winds from northeastern China carry the etiologic agent of Kawasaki disease from its source to Japan. PNAS. 2014;111:7952-7.

23. Sonobe T, Kiyosawa N, Tsuchiya K, Aso S, Imada Y, Imai Y, et al. Prevalence of coronary artery abnormality in incomplete Kawasaki disease. Pediatr Int. 2007:49:421-6

24. Manlhiot C, Christie E, McCrindle BW, Rosenberg H, Chahal N, Yeung RS. Complete and incomplete Kawasaki disease: two sides of the same coin. Eur J Pediatr. 2012;171:657-62.

25. Fujita Y, Nakamura Y, Sakata K, Hara N, Kobayashi M, Nagai M, et al. Kawasaki disease in families. Pediatrics. 1989;84:666-9.

26. Dergun M, Kao A, Hauger SB, Newburger JW, Burns JC. Familial occurrence of Kawasaki syndrome in North America. Arch Pediatr Adolesc Med. 2005. 159:876-81.
27. Nakamura Y, Yashiro M, Uehara R, Sadakane A, Tsuboi S, Aoyama Y, et al. Epidemiologic features of Kawasaki disease in Japan: results of the 20092010 Nationwide survey. J Epidemiol. 2012;22:216-21.

28. Park YW, Han JW, Hong YM, Ma JS, Cha SH, Kwon TC, et al. Epidemiological features of Kawasaki disease in Korea, 2006-2008. Pediatr Int. 2011;53:36-9.

29. Harada F, Sada M, Kamiya T, Yanase Y, Kawasaki T, Sasazuki T. Genetic analysis of Kawasaki syndrome. Am J Hum Genet. 1986;39:537-9.

30. Hirata S, Nakamura Y, Yanagawa H. Incidence rate of recurrent Kawasaki disease and related risk factors: from the results of nationwide surveys of Kawasaki disease in Japan. Acta Paediatr. 2001;90:40-4.

31. Uehara R, Yashiro M, Nakamura Y, Yanagawa H. Kawasaki disease in parents and children. Acta Paediatr. 2003;92:694-7.

32. Uehara R, Yashiro M, Nakamura Y, Yanagawa $H$. Parents with a history of Kawasaki disease whose child also had the same disease. Pediatrics Int. 2011:53:511-4.

33. Holve TJ, Patel A, Chau Q, Marks AR, Meadows A, Zaroff JG. Long-term cardiovascular outcomes in survivors of Kawasaki disease. Pediatrics. 2014; 133:e305-11.

34. Kitano N, Suzuki H, Takeuchi T, Suenaga T, Kakimoto N, Shibuta S, et al. Epidemiologic features and prognostic factors of coronary artery lesions associated with Kawasaki disease based on a 13-year cohort of consecutive cases identified by complete enumeration surveys in Wakayama, Japan. J Epidemiol. 2014;24:427-34

35. Chang FY, Hwang B, Chen SJ, Lee PC, Meng CC, Lu JH. Characteristics of Kawasaki disease in infants younger than six months of age. Pediatr Infect Dis J. 2006:25:241-4

36. Rigante D, Valentini P, Rizzo D, Leo A, De Rosa G, Onesimo R, et al. Responsiveness to intravenous immunoglobulins and occurrence of coronary artery abnormalities in a single-center cohort of Italian patients with Kawasaki syndrome. Rheumatol Int. 2010;30:841-6.

37. Moffett BS, Syblik D, Denfield S, Altman C, Tejtel-Sexson K. Epidemiology of immunoglobulin resistant Kawasaki disease: results from a large, national database. Pediatr Cardiol. 2015;36:374-8.

38. Nakamura Y, Aso E, Yashiro M, Tsuboi S, Kojo T, Aoyama Y, et al. Mortality among Japanese with a history of Kawasaki disease: results at the end of 2009. J Epidemiol. 2013:23:429-34.

39. Nakamura Y, Yashiro M, Uehara R, Sadakane A, Chihara I, Aoyama Y, et al. Epidemiologic features of Kawasaki disease in Japan: results of the 20072008 nationwide survey. J Epidemiol. 2010;20:302-7.

40. Huang WC, Huang LM, Chang IS, Chang LY, Chiang BL, Chen PJ, et al. Epidemiologic features of Kawasaki disease in Taiwan, 2003-2006. Pediatrics. 2009;123:e401-5.

41. Du ZD, Zhao D, Du J, Zhang YL, Lin Y, Liu C, et al. Epidemiologic study on Kawasaki disease Beijing from 2000 through 2004. Pediatr Infect Dis J. 2007; 26:449-51.

42. Ma XJ, Yu CY, Huang M, Chen SB, Huang MR, Huang GY. Epidemiologic features of Kawasaki disease in Shanghai from 2003 through 2007. Chin Med J (Engl). 2010;123:2629-34

43. Ng YM, Sung RY, So LY, Fong NC, Ho MH, Cheng YW, et al. Kawasaki disease in Hong Kong, 1994 to 2000. Hong Kong Med J. 2005;11:331-5.

44. Li XH, Li XJ, Li H, Xu M, Zhou M. Epidemiological study of Kawasaki disease in Sichuan province of China. J Trop Pediatr. 2008;52:133-6.

45. Singh S, Aulakh R, Bhalla AK, Suri D, Manojkumar R, Narula N, et al. Is Kawasaki disease incidence rising in Chandigarh, North India? Arch Dis Child. 2011;96:137-40.

46. Durongpisitkul K, Sandtawesin C, Khongphatthanayopthin A, Panamonta M, Sopontammarak S, Sittiwangkul R, et al. Epidemiologic study of Kawasaki disease and cases resistant to IVIG therapy in Thailand. Asian Pac J Allergy Immunol. 2006;24:27-32.

47. Holman RC, Christensen KY, Belay ED, Steiner CA, Effler PV, Miyamura J, et al. Racial/ethnic differences in the incidence of Kawasaki syndrome among children in Hawaii. Hawaii Med J. 2010;69:194-7.

48. Lin YT, Manlhiot C, Ching JC, Han RK, Nield LE, Dillenburg R, et al. Repeated systematic surveillance of Kawasaki disease in Ontario from 1995 to 2006. Pediatr Int. 2010;52:699-706.

49. Borzutzky A, Hoyos-Bachiloglu R, Cerda J, Talesnik E. Rising hospitalization rates of Kawasaki disease in Chile between 2001 and 2007. Rheumatol Int 2012;32:2491-5.

50. Harnden A, Mayon-White R, Perera R, Yeates D, Goldacre M, Burgner D. Kawasaki disease in England: ethnicity, deprivation, and respiratory pathogens. Pediatr Infect Dis J. 2009;28:21-4. 
51. Lynch M, Holman RC, Mulligan A, Belay ED, Schonberger LB. Kawasaki syndrome hospitalizations in Ireland, 1996 through 2000. Pediatr Infect Dis J. 2003;22:959-63.

52. Salo E. Kawasaki disease in Finland in 1982-1992. Scand J Infect Dis. 1993;25: 497-502.

53. Fischer TK, Holman RC, Yorita KL, Belay ED, Melbye M, Koch A. Kawasaki syndrome in Denmark. Pediatr Infect Dis J. 2007;26:411-5.

54. Schiller B, Fasth A, Bjorkhem G, Elinder G. Kawasaki disease in Sweden: incidence and clinical features. Acta Paediatr. 1995;84:769-74.

55. Heuclin T, Dubos F, Hue V, Godart F, Francart C, Vincent $P$, et al. Increased detection rate of Kawasaki disease using new diagnostic algorithm, including early use of echocardiography. J Pediatr. 2009;155:695-9.

56. Shulman ST, Rowley AH. Kawasaki disease: insights into pathogenesis and approaches to treatment. Nat Rev Rheumatol. 2015;11:475-82.

57. Kusuda T, Nakashima Y, Murata K, Kanno S, Nishio H, Saito M, et al. Kawasaki disease-specific molecules in the sera are linked to microbe-associated molecular patterns in the biofilms. PLoS One. 2014;9:e113054.

58. Naoe S, Takahashi K, Masuda H, Tanaka N. Kawasaki disease with particular emphasis on arterial lesions. Acta Pathol Jpn. 1991;41:785-973.

59. Harada K. Intravenous gamma-globulin treatment in Kawasaki disease. Acta Paediatr Jpn. 1991;33:805-10.

60. Orenstein JM, Rowley AH. An evaluation of the validity of the animal models of Kawasaki disease vasculopathy. Ultrastruct Pathol. 2014;38:245-7.

61. Takahashi K, Oharaseki T, Yokouchi Y, Naoe S, Saji T. Kawasaki disease: basic and pathological findings. Clin Exp Nephrol. 2013;17:690-3.

62. Manlhiot C, Millar K, Golding F, McCrindle BW. Improved classification of coronary artery abnormalities based only on coronary artery z-scores after Kawasaki disease. Pediatr Cardiol. 2010;31:242-9.

63. Straface E, Gambardella L, Metere A, Marchesi A, Palumbo G, Cortis E, et al Oxidative stress and defective platelet apoptosis in naïve patients with Kawasaki disease. Biochem Biophys Res Commun. 2010;392:426-30.

64. Ueno K, Nomura Y, Morita Y, Eguchi T, Masuda K, Kawano Y. Circulating platelet-neutrophil aggregates play a significant role in Kawasaki disease. Circ J. 2015:79:1349-56.

65. Sreeramkumar V, Adrover JM, Ballesteros I, Cuartero MI, Rossaint J, Bilbao I, et al. Neutrophils scan for activated platelets to initiate inflammation. Science. 2014;346:1234-8.

66. Sellge G, Kufer TA. PRR-signaling pathways: learning from microbial tactics. Semin Immunol. 2015;27:75-84.

67. Thomas CJ, Schroder K. Pattern recognition receptor function in neutrophils. Trends Immunol. 2013;34:317-28.

68. Cognasse F, Nguyen KA, Damien P, McNicol A, Pozzetto B, HamzehCognasse $\mathrm{H}$, et al. The inflammatory role of platelets via their TLRs and Siglec receptors. Front Immunol. 2015;6:83.

69. Newson J, Stables M, Karra E, Arce-Vargas F, Quezada S, Motwani M, et al. Resolution of acute inflammation bridges the gap between innate and adaptive immunity. Blood. 2014;124:1748-64.

70. Jia S, Li C, Wang G, Yang J, Zu Y. The T helper type 17/regulatory T cell imbalance in patients with acute Kawasaki disease. Clin Exp Immunol. 2010; 162:131-7.

71. Rasouli M, Heidari B, Kalani M. Downregulation of Th17 cells and the related cytokines with treatment in Kawasaki disease. Immunol Lett. 2014;162(1 Pt A):269-75.

72. Guo MM, Tseng WN, Ko CH, Pan HM, Hsieh KS, Kuo HC. Th17- and Tregrelated cytokine and mRNA expression are associated with acute and resolving Kawasaki disease. Allergy. 2015;70:310-8.

73. Raphael I, Nalawade S, Eagar TN, Forsthuber TG. T cell subsets and their signature cytokines in autoimmune and inflammatory diseases. Cytokine. 2015;74:5-17.

74. Hirabayashi Y, Takahashi Y, Xu Y, Akane K, Villalobos IB, Okuno Y, et al. Lack of $\mathrm{CD}^{+} \mathrm{CD} 25^{+} \mathrm{FOXP} 3^{+}$regulatory $T$ cells is associated with resistance to intravenous immunoglobulin therapy in patients with Kawasaki disease. Eur J Pediatr. 2013;172:833-7.

75. Shimizu C, Oharaseki T, Takahashi K, Kottek A, Franco A, Burns JC. The role of TGF- $\beta$ and myofibroblasts in the arteritis of Kawasaki disease. Hum Pathol. 2013;44:189-98

76. Onouchi Y. Genetics of Kawasaki disease: what we know and don't know. Circ J. 2012;76:1581-6.

77. Kuo HC, Chao MC, Hsu YW, Lin YC, Huang YH, Yu HR, et al. CD40 gene polymorphisms associated with susceptibility and coronary artery lesions of Kawasaki disease in the Taiwanese population. Sci World J. 2012;2012:520865
78. Yoon KL. Update of genetic susceptibility in patients with Kawasaki disease. Kor J Pediatr. 2015;58:84-8

79. Ulloa-Gutierrez R, Acón-Rojas F, Camacho-Badilla K, Soriano-Fallas A. Pustular rash in Kawasaki syndrome. Pediatr Infect Dis J. 2007;26:1163-5.

80. Langley EW, Kirse DK, Barnes CE, Covitz W, Shetty AK. Retropharyngeal edema: an unusual manifestation of Kawasaki disease. J Emerg Med. 2010;39:181-5.

81. Tona R, Shinohara S, Fujiwara K, Kikuchi M, Kanazawa Y, Kishimoto I, et al. Risk factors for retropharyngeal cellulitis in Kawasaki disease. Auris Nasus Larynx. 2014;41:455-8.

82. Kourda M, Bouaziz A, Tougourti MN. Necrotic lesions of the face in Kawasaki disease. Arch Pediatr. 2010;17:1667-9.

83. Binstadt BA, Levine JC, Nigrovic PA, Gauvreau K, Dedeoglu F, Fuhlbrigge RC, et al. Coronary artery dilation among patients presenting with systemiconset juvenile idiopathic arthritis. Pediatrics. 2005;116:e89-93.

84. Kikuta H, Taguchi Y, Tomizawa K, Kojima K, Kawamura N, Ishizaka A, et al. Epstein-Barr virus genome-positive $T$ lymphocytes in a boy with chronic active EBV infection associated with Kawasaki-like disease. Nature. 1988:333:455-7.

85. van Doorn HR, Lo-A-Njoe SM, Ottenkamp J, Pajkrt D. Widened coronary arteries in a feverish child. Pediatr Cardiol. 2006;27:515-8.

86. Bratincsak A, Reddy VD, Purohit PJ, Tremoulet AH, Molkara DP, Frazer JR, et al. Coronary artery dilation in acute Kawasaki disease and acute illnesses associated with fever. Pediatr Infect Dis J. 2012;31:924-6.

87. Muniz JC, Dummer K, Gauvreau K, Colan SD, Fulton DR, Newburger JW. Coronary artery dimensions in febrile children without Kawasaki disease. Circ Cardiovasc Imaging. 2013;6:239-44.

88. Falcini F, Ozen S, Magni-Manzoni S, Candelli M, Ricci L, Martini G, et al. Discrimination between incomplete and atypical Kawasaki syndrome versus other febrile diseases in childhood: results from an international registrybased study. Clin Exp Rheumatol. 2012;30:799-804.

89. Dillon MJ, Eleftheriou D, Brogan PA. Medium-size-vessel vasculitis. Pediatr Nephrol. 2010:25:1641-52

90. Brogan PA, Bose A, Burgner D, Shingadia D, Tulloh R, Michie C, et al. Kawasaki disease: an evidence based approach to diagnosis, treatment, and proposals for future research. Arch Dis Child. 2002;86:286-90.

91. Wilson N, Heaton P, Calder L, Nicholson R, Stables S, Gavin R. Kawasaki disease with severe cardiac sequelae: lessons from recent New Zealand experience. J Paediatr Child Health. 2004:40:524-9.

92. Suzuki A, Miyagawa-Tomita S, Komatsu K, Nakazawa M, Fukaya T, Baba K, et al. Immunohistochemical study of apparently intact coronary artery in a child after Kawasaki disease. Pediatr Int. 2004:46:590-6.

93. Wang W, Gong F, Zhu W, Fu S, Zhang Q. Macrophage activation syndrome in Kawasaki disease: more common than we thought? Semin Arthritis Rheum. 2015:44:405-10.

94. Ravelli A, Magni-Manzoni S, Pistorio A, Besana C, Foti T, Ruperto N, et al. Preliminary diagnostic guidelines for macrophage activation syndrome complicating systemic juvenile arthritis. J Pediatr. 2005:149:598-604.

95. Kang HR, Kwon YH, Yoo ES, Ryu KH, Kim JY, Kim HS, et al. Clinical characteristics of hemophagocytic lymphohistiocytosis following Kawasaki disease: differentiation from recurrent Kawasaki. Blood Res. 2013;48:254-7.

96. Kanegaye JT, Wilder MS, Molkara D, Frazer JR, Pancheri J, Tremoulet AH, et al. Recognition of a Kawasaki disease shock syndrome. Pediatrics. 2009:123:e783-9.

97. Yang HM, Du ZD, Fu PP. Clinical features of recurrent Kawasaki disease and its risk factors. Eur J Pediatr. 2013:172:1641-7.

98. Rigante D. Autoinflammatory syndromes behind the scenes of recurrent fevers in children. Med Sci Monit. 2009:15(8):RA179-87.

99. Newburger JW, Burns JC, Beiser AS, Loscalzo J. Altered lipid profile after Kawasaki syndrome. Circulation. 1991;84:625-31.

100. Cheung YF, Yung TC, Tam SC, Ho MH, Chau AK. Novel and traditional cardiovascular risk factors in children after Kawasaki disease: implications for premature atherosclerosis. J Am Coll Cardiol. 2004:43:120-4.

101. Dhillon R, Clarkson P, Donald AE, Powe AJ, Nash M, Novelli V, et al. Endothelial dysfunction late after Kawasaki disease. Circulation. 1996; 94:2103-6

102. McCrindle BW, Mclntyre S, Kim C, Lin T, Adeli K. Are patients after Kawasaki disease at increased risk for accelerated atherosclerosis? J Pediatr. 2007;151:244-8.

103. Cheung YF, Wong SJ, Ho MH. Relationship between carotid intima-media thickness and arterial stiffness in children after Kawasaki disease. Arch Dis Child. 2007;92:43-7. 
104. Cheung YF, Karmin O, Woo CW, Armstrong S, Siow YL, Chow PC, et al. Oxidative stress in children late after Kawasaki disease: relationship with carotid atherosclerosis and stiffness. BMC Pediatr. 2008 May 8;8:20.

105. Straface E, Marchesi A, Gambardella L, Metere A, Tarissi de Jacobis I, Viora M, et al. Does oxidative stress play a critical role in cardiovascular complications of Kawasaki disease? Antioxid Redox Signal. 2012;17:1441-6.

106. Minetti M, Agati L, Malorni W. The microenvironment can shift erythrocytes from a friendly to a harmful behavior: pathogenetic implications for vascular diseases. Cardiovasc Res. 2007;75:21-8

107. Research Committee on Kawasaki Disease. Report of Subcommittee on Standardization of Diagnostic Criteria and Reporting of Coronary Artery Lesions in Kawasaki Disease. Tokyo: Ministry of Health and Welfare; 1984

108. De Zorzi A, Colan SD, Gauvreau K, Baker AL, Sundel RP, Newburger JW. Coronary artery dimensions may be missclassified as normal in Kawasaki disease. J Pediatr. 1998;133:254-8.

109. McCrindle BW, Li JS, Minich LL, Colan SD, Atz AM, Takahashi M, et al. Pediatric Heart Network Investigators. Coronary artery involvement in children with Kawasaki disease: risk factors from analysis of serial normalized measurements. Circulation. 2007;116:174-9.

110. Joint Working Groups: the Japanese Circulation Society, The Japanese Society of Kawasaki Disease, The Japanese Association for Thoracic Surgery, The Japan Pediatric Society, The Japanese Society of Pediatric Cardiology and Cardiac Surgery, The Japanese College of Cardiology. Guidelines for Diagnosis and Management of Cardiovascular Sequelae in Kawasaki disease (JCS 2013). Circ J. 2014;78:2521-62.

111. Lega JC, Bozio A, Cimaz R, Veyrier M, Floret D, Ducreux C, et al. Extracoronary echocardiographic findings as predictors of coronary artery lesions in the initial phase of Kawasaki disease. Arch Dis Child. 2013;98:97-102.

112. Fuse S, Kobayashi T, Arakaki Y, Ogawa S, Katoh H, Sakamoto N, et al. Standard method for ultrasound imaging of coronary artery in children. Pediatr Int. 2010;52:876-82.

113. Leonardi B, Giglio V, Sanders SP, Pasceri V, De Zorzi A. Ultrasound tissue characterization of the myocardium in patients after Kawasaki disease. Pediatr Cardiol. 2010;31:766-72.

114. Duan Y, Wang X, Cheng Z, Wu D, Wu L. Application of prospective ECG triggered dual-source CT coronary angiography for infants and children with coronary artery aneurysms due to Kawasaki disease. Br J Radiol. 2012; 85:e1190-7.

115. Yu Y, Sun K, Wang R, Li Y, Xue H, Yu L, et al. Comparison study of echocardiography and dual-source CT in diagnosis of coronary artery aneurysm due to Kawasaki disease: coronary artery disease. Echocardiography. 2011;28:1025-34.

116. Ntsinjana HN, Tann O, Hughes M, Derrick G, Secinaro A, Schievano S, et al. Utility of adenosine stress perfusion CMR to assess paediatric coronary artery disease. Eur Heart J Cardiovasc Imaging. 2016; Epub ahead of print

117. Tacke CE, Kuipers IM, Groenink M, Spijkerboer AM, Kuijpers TW. Cardiac magnetic resonance imaging for noninvasive assessment of cardiovascular disease during the follow-up of patients with Kawasaki disease. Circ Cardiovasc Imaging. 2011;4:712-20.

118. Kim JW, Goo HW. Coronary artery abnormalities in Kawasaki disease: comparison between CT and MR coronary angiography. Acta Radiol. 2013; 54:156-63.

119. Newburger JW, Fulton DR. Kawasaki Disease. Curr Treat Options Cardiovasc Med. 2007:9:148-58

120. Dedeoglu R, Barut K, Oztunc F, Atik S, Adrovic A, Sahin S, et al. Evaluation of myocardial deformation in patients with Kawasaki disease using speckletracking echocardiography during mid-term follow-up. Cardiol Young. 2017; 27:1377-85.

121. Nakamura Y, Yashiro M, Uehara R, Sadakane A, Tsuboi S, Aoyama Y, et al. Epidemiologic features of Kawasaki disease in Japan: results of the 20092010 nation-wide survey. J Epidemiol. 2012;22:216-21.

122. Kobayashi T, Inoue Y, Takeuchi K, Okada Y, Tamura K, Tomomasa T, et al. Prediction of intravenous immunoglobulin unresponsiveness in patients with Kawasaki disease. Circulation. 2006;113:2606-12.

123. Sleeper LA, Minich LL, McCrindle BM, Li JS, Mason W, Colan SD, et al. Evaluation of Kawasaki disease risk-scoring systems for intravenous immunoglobulin resistance. J Pediatr. 2011;158:831-5.

124. Furusho K, Kamiya T, Nakano H, Kiyosawa N, Shinomiya K, Hayashidera T, et al. High-dose intravenous gammaglobulin for Kawasaki disease. Lancet. 1984;2:1055-8.
125. Newburger JW, Takahashi M, Burns JC, Beiser AS, Chung KJ, Duffy CE, et al. The treatment of Kawasaki syndrome with intravenous gamma globulin. N Engl J Med. 1986;315:341-7.

126. Newburger JW, Takahashi M, Beiser AS, Burns JC, Bastian J, Chung KJ, et al. A single intravenous infusion of gamma globulin as compared with four infusions in the treatment of acute Kawasaki syndrome. $\mathrm{N}$ Engl J Med. 1991;324:1633-9.

127. Oates-Whitehead RM, Baumer JH, Haines L, Love S, Maconochie IK, Gupta A, et al. Intravenous immunoglobulin for the treatment of Kawasaki disease in children. Cochrane Database Syst Rev. 2003;4:CD004000.

128. Leung DY, Cotran RS, Kurt-Jones E, Burns JC, Newburger JW, Pober JS Endothelial cell activation and high interleukin-1 secretion in the pathogenesis of acute Kawasaki disease. Lancet. 1989;2:1298-302.

129. Abe J, Jibiki T, Noma S, Nakajima T, Saito H, Terai M. Gene expression profiling of the effect of high-dose intravenous Ig in patients with Kawasaki disease. J Immunol. 2005;174:5837-45.

130. Terai M, Jibiki T, Harada A, Terashima Y, Yasukawa K, Tateno S, et al. Dramatic decrease of circulating levels of monocyte chemoattractant protein-1 in Kawasaki disease after gamma globulin treatment. J Leukoc Biol. 1999;65:566-72

131. Bayary J, Dasgupta S, Misra N, Ephrem A, Duong van Huyen JP, Delignat S, et al. Intravenous immunoglobulin in autoimmune disorders: an insight into the immunoregulatory mechanisms. Int Immunopharmacol. 2006;6:528-34.

132. Tse SM, Silverman ED, McCrindle BW, Yeung RS. Early treatment with intravenous immunoglobulin in patients with Kawasaki disease. J Pediatr. 2002;140:450-5.

133. Shamim I. Diagnosis and treatment of suspected Kawasaki disease before the fifth day of illness. Ped Inf Dis J. 2013;32:424.

134. Bonilla FA. Intravenous immunoglobulin: adverse reactions and management. J Allergy Clin Immunol. 2008;122:1238-9.

135. Nimmerjahan F, Ravetch J. Anti-inflammatory actions of intravenous immunoglobulin. Annu Rev Immunol. 2008;26:513-33.

136. Research Committee of the Japanese Society of Pediatric Cardiology and Cardiac Surgery Committee for Development of Guidelines for Medical Treatment of Acute Kawasaki Disease. Guidelines for medical treatment of acute Kawasaki disease: Report of the Research Committee of the Japanese Society of Pediatric Cardiology and Cardiac Surgery (2012 revised version). Pediatr Int. 2014;56:135-58.

137. Eleftheriou D, Levin M, Shingadia D, Tulloh R, Klein NJ, Brogan PA Management of Kawasaki disease. Arch Dis Child. 2013;99:74-83.

138. Terai M, Shulman ST. Prevalence of coronary artery abnormalities in Kawasaki disease is highly dependent on gamma globulin dose but independent of salicylate dose. J Pediatr. 1997;131:888-93.

139. Rigante D, Andreozzi L, Fastiggi M, Bracci B, Natale MF, Esposito S Critical overview of the risk scoring systems to predict nonresponsiveness to intravenous immunoglobulin in Kawasaki syndrome. Int J Mol Sci. 2016;17(3):278.

140. Hua W, Izurieta HS, Slade B, Belay ED, Haber P, Tiernan R, et al. Kawasaki disease after vaccination: reports to the vaccine adverse event reporting system 1990-2007. Pediatr Infect Dis J. 2009;28:943-7.

141. Abrams JY, Weintraub ES, Baggs JM, McCarthy NL, Schonberger LB, Lee GM Childhood vaccines and Kawasaki disease. Vaccine safety datalink, 19962006. Vaccine. 2015:33:382-7.

142. Esposito S, Rigante D, Principi N. The role of infection in Kawasaki syndrome. J Inf Secur. 2013:67:1-10.

143. Fitzgerald DA. Aspirin and Reye syndrome. Paediatr Drugs. 2007;9:205-6.

144. Phuong LK, Bonetto C, Buttery J, Pernus YB, Chandler R, Goldenthal KL, et al. Kawasaki disease and immunisation: standardised case definition \& guidelines for data collection, analysis. Vaccine. 2016;34:6582-659.

145. Esposito S, Bianchini S, Dellepiane RM, Principi N. Vaccines and Kawasaki disease. Expert Rev Vaccines. 2016;15(3):417-24.

146. Heijstek MW, Ott de Bruin LM, Borrow R, van der Klis F, Koné-Paut I, Fasth $A$, et al. Vaccination in paediatric patients with auto-immune rheumatic diseases: a systemic literature review for the European League against Rheumatism evidence-based recommendations. Autoimmun Rev. 2011;11:112-22.

147. Heijstek MW, Ott de Bruin LM, Bijl M, Borrow R, van der Klis F, Koné-Paut I, et al. EULAR recommendations for vaccination in paediatric patients with rheumatic diseases. Ann Rheum Dis. 2011;70:1704-12.

148. Dell'Era L, Esposito S, Corona F, Principi N. Vaccination of children and adolescents with rheumatic diseases. Rheumatology (Oxford). 2011;50:1358-65. 
149. Dell'Era L, Corona F, Daleno C, Scala A, Principi N, Esposito S. Immunogenicity, safety and tolerability of MF59-adjuvanted seasonal influenza vaccine in children with juvenile idiopathic arthritis. Vaccine. 2012:30:936-40.

150. Esposito S, Bruno C, Berardinelli A, Filosto M, Mongini T, Morandi L, et al. Vaccination recommendations for patients with neuromuscular disease. Vaccine. 2014;32:5893-900.

Ready to submit your research? Choose BMC and benefit from:

- fast, convenient online submission

- thorough peer review by experienced researchers in your field

- rapid publication on acceptance

- support for research data, including large and complex data types

- gold Open Access which fosters wider collaboration and increased citations

- maximum visibility for your research: over $100 \mathrm{M}$ website views per year

At $B M C$, research is always in progress.

Learn more biomedcentral.com/submissions 